\title{
IMMORALITY: SEBUAH STUDI BIBLIKAL-SISTEMATIS
}

Iman Kristina Halawa

imankristinahalawa@sttab.ac.id

\begin{abstract}
At present there are many moral deviations in human life. Moral deviations have permeated the human life, namely: in the fields of politics, economics, education, art, philosophy and the church. These deviations occur because of a lack of complete understanding of immorality. Therefore through this paper we will present phenomenologically moral deviations in several aspects of human life, then in this paper will discuss the roots of the phenomenon of moral deviance in a biblical-systematic manner. Because the author believes that the fact of immorality was present at the time of the Bible (PL \& amp; NT) and the Bible also provides facts about how God responds to the events of immorality that occur. So that through this writing believers can determine attitudes toward current immorality events according to how God stands in the Bible.
\end{abstract}

Keywords: Immorality, Study, Biblical-Systematic, God.

\begin{abstract}
Abstrak: Pada masa kini banyak penyimpangan moral dalam kehidupan manusia. Penyimpangan moral tersebut telah meresap ke dalam segi kehidupan manusia, yaitu: dalam bidang politik, ekonomi, pendidikan, seni, filsafat dan gereja. Penyimpangan tersebut terjadi oleh karena kurangnya pemahaman yang utuh mengenai immorality. Oleh karena itu melalui tulisan ini akan menyajikan secara fenomenologis penyimpangan moral dalam beberapa segi kehidupan manusia, selanjutnya dalam tulisan ini akan membahas akar terjadinya fenomena penyimpangan moral tersebut secara biblical-sistematis. Karena penulis menyakini bahwa fakta immorality telah hadir pada masa Alkitab (PL \&amp; PB) dan Alkitab juga memberikan fakta bagaimana Allah menyikapi peristiwa immorality yang terjadi. Sehingga melalui tulisan ini orang percaya dapat menentukan sikap terhadap peristiwa immorality masa kini sesuai dengan bagaimana sikap Allah dalam Alkitab.
\end{abstract}

Kata Kunci: immorality, Studi, Biblikal-Sistematis, Allah.

\section{PENDAHULUAN}

Manusia diciptakan Tuhan bagi kemuliaan Tuhan. Namun dalam Kejadian 3 manusia jatuh ke dalam dosa. Kejatuhan manusia ke dalam dosa membuat kondisi manusia rusak total (total depravity). Dosa telah mencemari hati nurani (conscience), pikiran (mind) dan keinginan manusia (will). Sehingga dalam sejarah kehidupan manusia paska kejatuhan tak henti-hentinya diwarnai dengan berbagai kehidupan dalam keberdosaan. Salah satu pola kehidupan yang diwariskan dari keberdosaan manusia ialah immorality. Allah telah menetapkan hukum moral namun manusia justru melanggar hukum moral tersebut. Oleh karena itu fenomena immorality tidak hilang begitu saja bahkan semakin mempengaruhi segala aspek kehidupan manusia, yaitu: dalam bidang politik, ekonomi, pendidikan, seni, filsafat bahkan Teologi. 
Dalam bidang politik kita bisa melihat banyak politikus yang jatuh dalam perbuatan tidak bermoral, contohnya: perselingkuhan para politikus karena telah memiliki kekuasaan dan kekayaan. Dalam dunia ekonomi immorality juga turut mewarnai kehidupan manusia, immorality mempengaruhi cara pandang para ekonom masa kini. Prinsip ekonomi manusia ditunggangi spirit hedonisme. Hedonisme adalah aliran etika yang mempertahankan bahwa tujuan segala tindak-tanduk manusia adalah kesenangan. ${ }^{1}$ Untuk mengerti bagaimana bentuk hedonisme masa kini, Ramly B. Lumintang menuliskan:

"Kesenangan yang dimaksud adalah kesenangan yang berkaitan dengan kepuasan hidup melalui: materi (harta), jabatan (kedudukan), pemuasan keinginan duniawi, dan pemenuhan kebutuhan psikologis. Di samping kesenangan sebagai tujuan hidup, kesenangan juga harus diraih, dicapai dan dinikmati sekarang ini. Untuk itu, semua penghalang kesenangan manusia harus disingkirkan termasuk moral, etika bahkan agama sekalipun. Kalau moral dan etika masih diperlukan, maka moral dan etika tersebut harus tanpa Allah". 2

Para ekonom didorong bukan hanya memikirkan sistem ekonomi tetapi juga memikirkan kejahatan dalam menciptakan sisitem ekonomi. Bahkan tega membagun ekonomi dengan cara-cara yang tidak bermoral. Contoh: demi kebutuhan ekonomi dibukalah tempat-tempat prostitusi yang jelas-jelas tidak bermoral dan penjualan serta memperkerjakan anak dibawah umur untuk kepentingan seks. Inilah kondisi immorality in mind set econom.

Dalam dunia pendidikan juga tidak luput dari influence of immorality. Para pendidik juga banyak jatuh dalam kasus yang tidak bermoral baik disekolah, maupun dalam kepribadian mereka. Contoh kasus ialah seorang guru yang mengajar namun terlibat dan memiliki penyimpangan seksual (LGBT), mahasiswa juga banyak jatuh dalam perbuatan immorality, contoh: banyak mahasiswa yang jatuh dalam pergaulan bebas, kecanduan pornografi dan hamil di luar nikah.

Dalam dunia seni juga tidak luput dari pengaruh immorality. Seni di sini yaitu seni musik, dan seni tari. Dari seni musik banyak lagu-lagu yang diciptakan penuh dengan syair-syair yang mendorong manusia untuk terlibat dalam tindakan amoralitas. Contoh

\footnotetext{
${ }^{1}$ Henk Ten Napel, Kamus Teologi (Jakarta: BPK. Gunung Mulia), 158

${ }^{2}$ Ramly B. Lumintang, Bahaya Postmodernisme Dan Peranan Kredo Reformed (Batu: Departemen Literatur PPII, 2010), 157
} 
dalam konteks Indonesia: musik-musik lagu Jambrud yang banyak di isi syair yang erotis. Pada masa kini ada beberapa kelompok band Rock yang menunjukkan aktifitas yang menentang Yesus Kristus, baik dari segi moral maupun syair. Banyak band-band rock yang membudayakan seks bebas, homoseksual, lesbianisme, kawin cerai, dan berbagai jenis perzinahan lainya. ${ }^{3}$ Lalu dalam dunia seni tari masa kini telah menjamur para penaripenari yang menampilkan aksi yang erotis yang tidak bermoral, baik dari gerakan maupun dari kostum yang digunakan. Dance modern diciptakan namun demi mendongkrak popularitas mereka rela menampilkan hal-hal yang tidak bermoral demi mendapatkan keuntungan dan nama.

Dalam dunia filsafat juga banyak menunjukkan tindakan yang tidak bermoral. Sebagai contoh pemahaman Gnostisime yang mengajarkan bahwa roh terpenjara dalam tubuh jadi roh lebih berharga daripada tubuh, oleh karena itu roh harus dibebaskan dari tubuh agar menemukan kebahagiaan. Akibat ajaran ini maka banyak orang Kristen pada abad mula-mula tidak menghargai tubuhnya, sehingga mereka terjebak dalam sikap hidup yang amoralitas. Pada masa kini berkembang filsafat postmodernisme, Stanley J. Grenz menjelaskan, bahwa: "yang lebih radikal adalah penolakan postmodernisme terhadap usaha menemukan kebenaran yang universal. Etos postmodern lahir dari keyakinan tidak adanya totalitas utuh yang dapat kita sebut realitas". ${ }^{4}$ Sehubungan dengan itu Ramly B. Lumintang juga menuliskan kandungan dari filsafat postmodernisme seperti humanisme, perspektifisme, subjektifisme, relatifisme, hedonism, konsumerisme dan sektarianisme. ${ }^{5}$

Melihat pengaruh immorality yang telah menjangkau sampai ranah filsafat maka kehidupan Gereja juga terancam oleh immorality. Dalam sejarah Reformasi, Gereja diperhadapkan oleh masalah moral dan doktrinal, secara moral para klerus terjatuh dalam tindakan amoralitas. ${ }^{6}$ Gereja Katolik Roma mengalami kemerosotan dalam pengajaran doktrinal, etika moral dan sosial. ${ }^{7}$ Dalam Buku Be A Good Minister of Christ yang ditulis oleh Pdt. G. Sudarmanto, D.Th., D.C.L juga menuliskan bahwa Gereja masa kini juga diperhadapkan dengan tantangan moral dan doktrinal. Mengenai masalah moral beliau menuliskan:

\footnotetext{
3 John Handol, Nyayian Lucifer, (Yogyakarta: ANDI, 2002), 140

${ }_{5}^{4}$ Stanley J. Grenz, A Primer On Postmodernism, (Yogyakarta: ANDI Offset, 2009), 266

${ }^{5}$ Ramly B. Lumintang, Bahaya Postmodernisme...., 365 $1997), 113$

6 Dietrich Kuhl, Sejarah Gereja: Gereja Katalik Roma Jilid 2 (Batu: Departemen Literatur YPPII,

7 B.K. Kuiper, The Church in History, (Malang: Gandum Mas, 2010), 50
} 
"Benteng moralitas para pelayan Kristus, baik fultimer maupun part timer, telah diruntuhkan oleh kenikmatan seks sesaat, kekuasaan fana, popularitas semu dan keserakahan materialistis. Bukan rahasia lagi, bahwa banyak pelayan Kristus telah tersandung skandal seksual. Akibatnya, dirinya dipermalukan, rumah tangganya kacau, pelayanannya hancur berantakan."8

Fenomena amoralitas seksual tersebut juga pernah hadir dalam kelompok yang mengklaim sebagai aliran keKristenan. Salah satunya tindakan amoral yang dilakukan oleh pengikut the Children of God yang menerapkan penginjilan dengan seks (flirty fishing). ${ }^{9}$ Melihat dua sudut pandang persoalan Gereja tersebut maka sangat berkaitan erat antara moral dan doktrinal. Doktrin yang salah akan menghasilkan tindakan yang salah.

Dari beberapa bidang kehidupan manusia telah terbukti bahwa immorality telah mempengaruhi (influence) pola kehidupan manusia. Oleh karena itu dalam tulisan ini pada tulisan ini akan merumuskan berdasarkan Alkitab bagaimana Allah memandang fakta immorality yang terjadi dalam kehidupan manusia dan bagaimana cara Allah menyelesaikan masalah immorality dalam kehidupan manusia, setelah itu melalui datadata Alkitab akan menuliskan bagaimana konsep immorality dan sikap orang percaya terhadap immorality.

\section{DEFINISI IMMORALITY}

Sebelum membahas apa saja yang termasuk dalam fakta immorality dalam Alkitab. Terlebih dahulu penting untuk mengerti arti kata immorality dalam Alkitab, sehingga kita dapat menentukan batas-batas dalam pembahasan selanjutnya. Kata immorality dalam bahasa Inggris merupakan kata benda (noun) yang memiliki arti dalam bahasa Indonesia adalah tunasusila, ketidaksopanan dan pelanggaran susila. ${ }^{10}$ Dalam membentuk definisi immorality penulis memakai dua kata dalam PB, yaitu aselgeia dan porneia. Di dalam Alkitab kata aselgeia diartikan ketidaksopanan hanya terdapat di dalam 2 Korintus 12: $21{ }^{11}$ Kata ini merupakan kata benda (noun), feminim, tunggal dan datif. ${ }^{12}$ Dalam PB kata tersebut ditulis sebanyak 10 kali (lih. Mrk. 7: 22, Rm. 13: 13, 2 Kor. 12:

${ }^{8}$ Gunaryo Sudarmanto, Be A Good Minister of Christ (Batu: Departemen Literatur YPPII, 2009)

${ }^{9}$ Ruth A. Tucker, Another Gospel, (Malang: Gandum Mas, 2007), 323

10 John m. Echols \&amp; Hassan Shadily, Kamus Inggris Indonesia (Jakarta: PT. Gramedia, 2010), 312

11 D.F. Walker, Konkordansi Alkitab (Jakarta: PT. BPK. Gunung Mulia, 2009), 441

${ }^{12}$ Hasan Sutanto, Perjanjian Baru Interlinear Yunani-Indonesia dan Konkordansi Perjanjian Baru (PBIK) Jilid I (Jakarta: Lembaga Alkitab Indonesia, 2010), 998 
21, Gal. 5: 19, Ef. 4: 19, 1Ptr. 4: 3, 2Ptr 2: 2, 8, 18 dan Yud. 1: 4). Dalam buku A GreekEnglish Lexicon of The New Tesatament menuliskan arti kata aselgeia, yaitu:

1. Licentiousness, debauchery, sesuality in singular and plural. Give one self over to debauchery Eph. 4: 19. Live licentiously 1Ptr. 4: 3. Pervert favor into licentiousness Jd. 4. Follow the inclination to sensuality 2Ptr. 2: 2.Esp. of sexual excesses Rm. 13: 13, 2Cor. 12: 21, Gal. 5: 19, in a long catalogue of vices, like mrk. 7: 22 , in decent conduct 2 ptr. $2: 7 .^{13}$

Jadi kata aselgeia tersebut diartikan perbuatan tidak bermoral berhubungan dengan seksualitas. ${ }^{14}$ Selanjutnya kata porneia yang diartikan pornografi. G. Sudarmanto menjelaskan kata pronografi terdiri dari dua kata, yaitu porneia dan 'graphe'. Porneia ialah seksualitas yang tak bermoral atau tak beretika (sexual immorality) dan 'graphe' artinya kitab atau tulisan. Jadi pornografi dapat dikatakan sebagai tulisan yang memakai kata-kata yang bersangkutan dengan seksualitas atau penggambaran tentang seksualitas yang tak bermoral. ${ }^{15}$

Jadi immorality adalah penyimpangan moral yang melibatkan unsur seksualitas dan dimotivasi kepuasan seksual semata baik dilakukan pribadi atau pun kelompok. Melalui definisi ini penulis akan mengangkat kasus-kasus dalam Alkitab yang mengindikasikan adanya tindakan yang immorality.

\section{FAKTA-FAKTA IMMORALITY DALAM ALKITAB DAN SIKAP ALLAH TERHADAP PERISTIWA TERSEBUT}

Perjanjian Lama dan perjanjian baru banyak mencatat peristiwa dan prinsip-prinsip yang bersangkut paut dengan immorality yang di dalamnya mengandung unsur perzinahan atau percabulan, dan dalam setiap peristiwa tersebut kita juga melihat keunikan cara Allah menangani problematika immorality yang dilakukan setiap tokoh Alkitab. Berikut beberapa fakta immorality dan bagaimana sikap Allah terhadap peristiwa tersebut.

\section{$\underline{\text { Lamekh yang mengambil istri dua orang (Kej. 4: 19) }}$}

\footnotetext{
${ }^{13}$ Direvisi oleh F. Wilbur Gingrich dan Frederick W. Danker, A Greek-English Lexicon of The New Testament and other Early Christian Literature (Chicago: The University of Chicago Press, 1987), 114

${ }^{14}$ Hasan Sutanto, Perjanjian Baru Interlinear Yunani-Indonesia dan Konkordansi Perjanjian Baru (PBIK) Jilid II (Jakarta: Lembaga Alkitab Indonesia, 2010), 122

${ }^{15}$ Robert S. Borong, Etika Seksual Kontemporer (2006), 39
} 
Alkitab memberikan penjelasan terperinci mengenai riwayat Lamekh, tokoh terakhir dari enam tokoh yang disebutkan dalam keturunan Kain (Kej. 4:19-24). Menurut Johan P. Lange akar kata untuk nama Lamekh tidak jelas. Jika kita menyelidiki nama itu berdasarkan bahasa Arab, nama tersebut berarti 'orang muda yang berkekuatan besar' atau 'penindas' atau 'orang yang kuat' dengan melihat arti namanya diindikasikan bahwa Lamekh ialah orang sombong yang membanggakan kekuatan dirinya. ${ }^{16}$ Setelah kejatuhan Adam, sejarah kejahatan yang sedang bertumbuh semakin besar diperlihatkan oleh Lamekh. Abraham Park dalam bukunya Sejarah Penebusan: Silsilah Di Kitab Kejadian menuliskan: Lamekh mencemarkan prinsip perkawinan suci menjadi prinsip kedagingan dan praktik hedonistik. Selanjutnya Abaraham Park juga menuliskan bahwa Lamekh adalah seorang cabul yang mempunyai dua istri. ${ }^{17}$ Bagaimana sikap Allah terhadap kehidupan Lamekh? Di dalam Alkitab tidak ditemukan bahwa Allah langsung menghukum Lamekh namun Alkitab menyatakan bahwa buah dari kehidupan Lamekh yang cabul ia memiliki anak-anak yang juga mewarisi keadaan hidup yang berdosa pula. ${ }^{18}$ Sehingga menunjukkan keturunan Kain terus menerus hidup dalam dosa.

\section{Tindakan Amoral penduduk Sodom Dan Gomora (Kej. 19: 5)}

Mengenai tindakan immorality penduduk Sodom dan Gomora Matthew Henry menuliskan:

"bahwa mereka semua jahat (ay. 4). Kejahatan dilakukan oleh semua orang, dan mereka sepakat dalam setiap maksud keji. Di sini yang tua dan yang

16 Johann Peter Lange, Commentary on Holy Scripture: Critical, Doctrinal and HomileticalGenesis, Trans. And ed. Philif Schaff (Grand Rapids: Zondervan, 1893), 261

17 Abraham Park, Sejarah Penebusan: Silsilah Di Kitab Kejadian Vol. 1 (Jakarta: PT. GRASINDO,2013), 77-78

18 Abraham Park menuliskan Lamekh mewariskan kepada anak-anaknya peradaban yang berlatar belakang pertengkaran dan pembunuhan. Anak-anak lelaki yang dilahirkan Ada, istri pertama Lamekh adalah Yabal dan Yubal. Nama Yabal berarti memimpin, memindahkan atau mencari tempat yang lembab. Kata ternak memiliki arti pekerjaan Yabal ialah penjual ternak dan masa itu telah hadir persaingan dalam kehidupan manusia. Selanjutnya Yubal artinya bunyi atau musik. Dia menjadi musisi yang memainkan kecapi dan suling. Namun musiknya bukanlah musik yang benar untuk memuji Allah, melainkan bunyi yang digunakan untuk berpesta pora dan bersenang-senang. Zaman ini warisan hidup hedonistik mulai terlihat. Hal tersebut dilihat dari kata Ibrani untuk Suling ialah ugab yang berasal dari kata kerja agab yang berarti tenggelam ke dalam cinta (berahi). Lalu anak-anak dari zila yaitu Tubal-Kain dan Naama. Tubal-Kain menjadi pandai besi. Kata Tubal-Kain merupakan gabungan dari kata Tubal dan Kain. Tubal dari akar kata bahasa Arab artinya meluap-luap dan Kain menunjukkan keinginan Lamekh akan kemakmuran bagi keturunan dari garis keturunan Kain. Tubal-Kain melebur dan menajamkan peralatan-peralatan besi, tetapi tidak digunakan sebagai alat-alat pertanian atau alat-alat perdamaian, melainkan sebagai senjata pembunuh untuk bagi ayahnya, Lamekh. Anak perempuan Lamekh Naama, arti namanya ialah menyenangkan, manis, canti (sangat menyolok). Biasanya nama anak perempuan tidak diikut sertakan dalam tradisi kuno. Namun nama Naama tercatat menunjukkan bahwa Naama adalah tokoh yang sangat menyolok dalam kecantikan kenikmatan, dan nafsu berahi tanpa ada sedikitpun hubungan dengan kesalehan. Abraham Park, Sejarah Penebusan...., 80-81 
muda, dan dari seluruh kota, ikut serta dalam kericuhan ini. Yang tua tidak melewatkannya, dan yang muda segera menghampirinya." 19

Selanjutnya Matthew Henry juga menuliskan bahwa kejahatan mereka telah sampai pada puncak tertinggi, mereka telah sangat berdosa kepada TUHAN (Kej. 13: 13). Kejahatan yang mereka ingin lakukan saat itu adalah kejahatan yang paling tidak wajar dan buruk sekali, dosa mereka disebut sebagai sodomi. Itu dilakukan tanpa pikir panjang dengan hawa nafsu yang memalukan (Rom. 1: 26- 27). Mereka juga tidak malu mengakuinya dan tidak malu melaksanakan keinginan tersebut dengan paksaan dan kekerasan. Lalu ketika Lot mencoba menengahi mereka dengan lemah lembut justru mereka semakin kasar terhadap Lot. $^{20}$

Bagaimana sikap Tuhan terhadap keadaan kota Sodom dan Gomora?. Tuhan memutuskan untuk menunggang balikkan kota Sodom dan Gomora karena kejahatan immorality. Cara Allah dalam menangani kasus di Sodom dan Gomora dengan menurunkan hujan belerang dan api (Kej. 19: 24-25). Mengenai hukuman tersebut Henry menuliskan:

Itu adalah hukuman yang menjawab dosa mereka. Hawa nafsu yang berkobarkobar melawan alam dihukum secara adil dengan kobaran api yang melampaui ala mini. Orang-orang yang mengejar kepuasan tidak wajar dihancurkan dengan api yang tidak wajar (Yud. 1:7). Mereka menganiaya malaikat-malaikat dengan perusuh-perusuh mereka, dan membuat Lot ketakutan, dan sekarang Allah menganiaya mereka dengan badai-Nya, dan membuat mereka ketakutan dengan putting beliung-Nya (Mzm. 83:16). Itu dimaksudkan untuk penyataan tetap tentang murka Allah terhadap dosa dan orang-orang berdosa di segala zaman. Karena itu hukuman ini sering dirujuk di dalam Alkitab, dan dijadikan pola untuk kehancuran Israel pula (Ul. 29:23), Babel (Yes. 13:19), Edom (Yer. 49:17-18), Moab dan Amon (Zef. 2:9). Bahkan itu merupakan lambing siksaaan api kekal (Yud. 1:7), dan kehancuran semua yang hidup fasik (2Ptr. 2:6), terutama yang memandang renda Injil (Mat. 10:15). ${ }^{21}$

Dari peristiwa tersebut menunjukkan bahwa Tuhan turun tangan langsung menyelesaikan permasalahan immorality. Maka benarlah firman Tuhan yang menyatakan bahwa Allah itu Kudus maka umat-Nya juga harus kudus.

\footnotetext{
19 Matthew Henry, Kitab Kejadian (Surabaya: Momentum, 2014), 419-420

${ }^{20}$ Ibid,..., 420

21 Matthew Henry, Kitab Kejadian,...., 429
} 


\section{Lot Dan Kedua Anaknya (Kej. 19:30-38)}

Dalam konteks Alkitab setelah penghukuman kota Sodom dan Gomora Lot membawa kedua anaknya tinggal di gua. Kedua anak perempuan Lot ingin meneruskan keturunan bagi ayahnya, namun tidak ada laki-laki lain ditempat mereka, sehingga kedua anak perempuan Lot merencanakan untuk tidur dengan ayah mereka untuk menyambung keturunan, anak-anak mereka menjadi Bapa orang Moab dan orang Amon. Mathhew Henry menuliskan:

"Perhatikanlah, walaupun kelahiran-kelahiran yang menguntungkan dapat diperoleh akibat hubungan badan sesama saudara sekandung, namun itu tidak membenarkan perbuatan tersebut. kelahiran demikian justru mengabadikan penghinaan dan mewariskan nama buruk kepada keturunan. Sekalipun begitu, suku Yehuda, suku asal Tuhan kita, adalah keturunan dari kelahiran yang seperti itu, dan Rut, seorang Moab, disebut namanya dalam silsilah-Nya (Mat.1:5,5).",22

Bagaimana sikap Allah terhadap peristiwa demikian? Alkitab menuliskan Lot tetap mendapat keturunan dari peristiwa tersebut namun namanya tidak dikenang sebagai tokoh iman, dimana ia telah berhasil mempertahankan kekudusan dalam hidupnya saat menghadapi tekanan sosial dari warga Sodom namun justru ia jatuh oleh anak-anaknya sendiri. Mathhew Henry mengomentari bahwa setelah perisriwa immorality tersebut tidak ada lagi Alkitab membahas mengenai kehidupan Lot, pastilah dia bertobat dan diampuni. Namun dari kebisuan Alkitab tentang Lot sejak peristiwa itu terjadi menunjukkan Lot dilupakan dan gagal dikenang dalam kehormatan. ${ }^{23}$ Dalam Ibrani 11 nama Lot tidak dituliskan dalam tokoh-tokoh iman, padahal dalam sejarah Lot mempertahankan agar hidupnya tidak sama dengan orang-orang Sodom. Hal tersebut menunjukkan bahwa immorality mebuat Lot gagal mendapatkan kualifikasi sebagai orang yang layak diteladani.

\section{Peristiwa Pemerkosaan Dina Oleh Sikhem (Kej. 34:1-5)}

Peristiwa ini terjadi antara Dina yang merupakan anak Yakub yang dilahirkan oleh Lea dan Sikhem anak Hemor raja negeri Hewi yang tinggal di Padang Aram. Fakta immorality terlihat ketika Sikhem melakukan pemerkosaan terhadap Dina. Latar belakangnya oleh karena Sikhem terikat hatinya oleh Dina, hal tersebut menunjukkan bahwa cinta yang didasarkan nafsu telah mendorong Sikhem gagal menjaga kekudusan.

\footnotetext{
${ }^{22}$ Matthew Henry, Kitab, ...., 437

23 Ibid,..., 437
} 
Cinta tersebut membuahkan dosa immorality, dimana tindakan Sikhem mengandung unsur pemaksaan, perlakuan tidak senonoh dan telah berbuat noda. ${ }^{24}$

Lalu bagaimana penyelesaian masalah immorality tersebut?. Yakub tahu karakteristik anak-anaknya yang mudah meluap amarahnya. Yakub berusaha mendiamkan masalah tersebut dan menyelesaikannya dengan damai dengan sebuah acara pernikahan. Dalam Kejadian 34:6-12 menunjukkan adanya sebuah kesepakatan damai yang dibuat untuk menikahkan anak Yakub dan Hemor. Namun saudara-saudra dari Dina tidak menerima kesepakatan tersebut dengan dalih agama akhirnya mereka mencoba membuat tipu muslihat untuk menumpas keluarga Hemor (lih. Ay. 13, 25, 26). Wycliffe menuliskan:

"Pada saat upacara tersebut dilaksanakan, Simeon dan Lewi memimpiun sebuah penyerbuan ke kota itu. Putra-putra Yakub kemudian membantai semua laki-laki Sikhem sementara mereka tidak berdaya untuk bertempur, lalu merampas keluarga dan harta miliki mereka. Di dalam sejarah keluarga leluhur Israel, pasal ini merupakan pasal yang kotor penuh nafsu serakah, kekejaman dan tindakan yang memalukan." 25

Penyelesaian masalah ini merupakan sebuah keunikan di satu sisi perbuatan immorality memang harus dihukum tegas, namun terkadang banyak cara tak terduga untuk menghukumnya. Reaksi sosial ambil bagian dalam tindakan tersebut, di mana manusia yang telah berdosa memiliki potensi besar untuk melakukan dosa. Sehingga tindakan main hakim sendiri bisa saja terjadi dengan memanipulasi atas dasar hukum agama. Namun tindakan Yakub yang tidak terlalu pusing dengan penodaan tersebut juga salah, sehingga kediamannya menumbuhkan reaksi yang tak terduga dari anak-anaknya. Namun Abraham Park menuliskan peristiwa yang terjadi pada Yakub karena ia melupakan nazarnya kepada Tuhan. $^{26}$ Pada prinsipnya immorality mendapatkan penghukuman di hadapan Allah, Tuhan dapat menggunakan banyak sarana untuk menyatakan kebenaran dan kekudusannya.

24 Dalam Wycliffe Commentary menuliskan kata laqah dilarikannya (ay.2) menunjukkan bahwa Dina diambil Sikhem dengan memakai kekuatan yang membuatnya tidak berdaya. Kata ana artinya diperkosa menunjukkan perlakuan yang tidak senonoh. Lalu kata nebala artinya berbuat noda menunjuk kepada sebuah perbuatan yang memalukan, najis dan bodoh. Ed. Charles F. Pfeiffer dan Everett F. Harrison, The Wycliffe Bible Commentary (Malang: Gandum Mas, 2011), 117

${ }_{25}$ Ed. Charles F. Pfeiffer dan Everett F. Harrison, The Wycliffe, ...., 118

26 Yakub seharusnya kembali ke Betel segera setelah ia membeli tanah Sikhem. Akan tetapi, ia lupa tentang nazarnya yang dilakukan di Betel dan bahkan setelah sepuluh tahun berlalu sejak ia kembali ke Kanaan dari Padang-Aram, ia terus tinggal di Sikhem. Semua hal tragis yang menimpa Yakub ini disebabkan oleh ketidakpercayaan Yakub yang telah melupakan nazarnya yang telah di Betel. Abraham Park, Sejarah Penebusan: Pertemuan Yang Tak Terlupakan (Jakarta: PT. GRASINDO, 2012), 123 


\title{
Peristiwa Tamar Tidur Dengan Mertuanya Yehuda (Kej. 38: 12- 19)
}

Sebuah peristiwa terjadi dalam kehidupan keluarga Yehuda di mana menantunya Tamar tidak memiliki suami lagi, karena anak Yehuda dari perempuan Kanaan bernama Syua, yaitu Er dan Onan sudah meninggal. Yehuda sudah berjanji akan memberikan Syela jika dia dewasa namun Yehuda tidak memberikannya juga kepada Tamar. Sehingga Tamar membuat siasat dengan cara tidur bersama mertuanya sendiri. Mengenai keadaan tersebut Matthew Henry menuliskan:

"Yehuda sudah menguburkan istrinya. Dan orang yang menduda perlu berjagajaga dengan kewaspadaan dan tekad yang besar untuk melawan semua nafsu kedagingan. Ia berlaku tidak adil terhadap menantunya, entah melalui kelalaian atau karena sengaja, dengan tidak memberikan anaknya yang masih hidup kepada dia, dan ini membuat menantunya terbuka terhadap godaan.",27

Jadi Tamar yang menyamar menjadi pelacur ${ }^{28}$ dan dihampiri oleh Yehuda, hal tersebut juga membongkar natur sifat Yehuda yang masih suka melakukan tindakan yang immorality, karena melakukan perbuatan zinah dengan menantunya. Tamar juga salah karena tidak bisa menahan ambisinya untuk memiliki anak atau hanya karena nafsu. Yehuda mendengar berita bahwa menantunya Tamar telah hamil tiga bulan dan akan membakarnya karena persundalannya. Namun Tamar menunjukkan bukti berupa "cap meterai, kalung dan tongkat" milik Yehuda. Melalui benda itu Yehuda tidak dapat berdalih lagi dan mengakui perbuatan zinahnya (Kej. 38:26). Mengenai peristiwa terbongkarnya aib Yehuda, Matthew Henry menuliskan:

\begin{abstract}
"Rasa malu Yehuda, ketika diperlihatkan bahwa dialah penzinahnya. Tamar mengeluarkan cap meterai serta kalung di depan pengadilan, yang membenarkan bahwa Yehudalah ayah dari anak yang dikandungnya (ay. 2526). Perhatikanlah, kefasikan yang sudah diperbuat dengan sangat rahasia, dan yang disembunyikan dengan amat sangat rapi, kadang-kadang dibukakan secara menakjubkan, aib dan kebingungan orang-orang yang sudah berkata, tidak ada yang melihat. Burung di udara mungkin akan menyampaikan ucapanmu. Namun, bagaimana pun juga, akan datang hari yang menghancurkan, ketikan semuanya akan dibukakan."29
\end{abstract}

Bagaimana Tuhan membereskan dosa immorality Yehuda? Alkitab membukakan bahwa dosa immorality merupakan dosa yang memalukan. Siapa yang melakukannya harus dengan sembunyi-sembunyi dan jika terungkap maka akan sangat

27 Matthew henry, Kitab, ....,735

28 Istilah pelacur ditulis dalam bahasa Ibrani kedeshot artinya pelacur religius. Ed. Charles F. Pfeiffer dan Everett F. Harrison, The Wycliffe, ...., 124

${ }^{29}$ Matthew Henry, Kitab...., 739 
memalukan dan menjatuhkan citra diri orang yang melakukan. Allah mempermalukan Yehuda sehingga di depan pengadilan bukti yang kuat menyatakan bahwa Yehuda telah berzinah, namun Allah masih memelihara Yehuda dengan tidak membuat orang-orang disekitarnya menghukum mati Yehuda (bdg. Pernyataan Yehuda dalam Kej. 38:24 yang menuntut agar Tamar dibakar). Kemurahan hati Allah terlihat dengan membuat Yehuda mengakui dosanya dan akhirnya anak hasil hubungan gelap tersebut yaitu Peres dan Zerah tetap terpelihara hidupnya, dimana Peres namanya tercatat sebagai generasi yang menurunkan Mesias (Mat. 1:3).

Peristiwa Onan Yang Menolak Memberi Keturunan Kepada Tamar (Kej. 38: 8- 10).

Dalam peristiwa tersebut Onan menikahi Tamar sebagai pengganti kakaknya Er yang telah meninggal. Namun Onan melakukan kejahatan, yaitu ia menolak membangkitkan keturunan bagi kakaknya yang telah meninggal. Cara yang dilakukan oleh onan ialah dengan membiarkan air maninya terbuang ketika bersetubuh dengan Tamar, mengenai hal ini Matthew Henry menuliskan:

"Onan, meskipun setuju untuk menikahi janda itu, namun dengan sangat melecehkan tubuhnya sendiri, melecehkan istrinya yang sudah dinikahinya, dan melecehkan kenangan akan kakaknya yang sudah meninggal, menolak membangkitkan keturunan bagi kakaknya, sebagaimana yang sudah menjadi kewajibannya." 30

Lalu lebih tegas lagi Matthew Henry juga menuliskan bahwa dosa-dosa yang tidak menghormati tubuh dan yang menajiskannya sangat tidak berkenan kepada Allah, dan merupakan bukti dari nafsu-nafsu yang kotor. $^{31}$ Jadi kejahatan immorality yang dilakukan Onan ialah menajiskan dirinya dengan nafsu-nafsu kotor yaitu membuang air mani agar tidak memberi keturunan. Bagaimana Allah menyiakapinya? Alkitab menuliskan bahwa Onan dihukum mati oleh Tuhan hal tersebut menunjukkan bahwa Allah yang kudus menentang kejahatan immorality.

\section{Peristiwa Daud Berzinah Dengan Betsyeba (2Sam. 11: 1- 5)}

Daud pada waktu berdiri di atas sotoh rumah ia melihat Betsyeba, lalu ia mengingini Betsyeba dan tidur dengan dengan Betsyeba. G. Sudarmanto menuliskan kejatuhan Daud dalam perzinahan oleh karena Daud melihat, mengingini dan tidur dengan

\footnotetext{
30 Ibid,..., 734

31 Mathhew Henry, Kitab...., 734
} 
Betsyeba. ${ }^{32}$ Kejatuhan Daud Dalam perzinahan bukan semata-mata karena kesalahan Daud namun juga karena adanya partisipasi dari Betsyeba ia datang atas panggilan Daud tanpa ragu-ragu dan tidak menolak keinginan Daud. ${ }^{33}$ Buah dari perzinahan tersebut membuat kesepakatan jahat antara Daud dan Yoab untuk menempatkan Uria suami Betsyeba dalam barisan perang terdepan yang membuat Uria tewas dalam peperangan. Hal itu menujukkan perbuatan immorality yang disembunyikan bisa melahirkan kebohongan yang lain, bahkan bisa merancangkan kejahatan bagai sesama manusia.

Bagaimana Allah menyikapi perbuatan immorality Daud dan Betsyeba?. Dalam konteks ini sudah ada sepuluh hukum yang diberikan Allah kepada Musa di gunung Sinai, salah satu hukum tersebut menuliskan bahwa jangan berzinah (Kel. 20: 14), dengan adanya hukum ini Allah juga menuntut tanggung jawab dari manusia atas apa yang dilakukannya. Alkitab menuliskan bahwa Allah mengutus nabi Natan untuk menegur dosa Daud, Allah menghukum Daud dengan menulahi anak pertama yang dilahirkan melalui hubungan Daud dan Betsyeba sehingga pada hari yang ketujuh matilah anak itu (Lih. 2Sam. 12: 15-18). Dalam kasus ini menunjukkan bahwa Allah memberi kesempatan hidup kepada Daud, oleh karena Allah telah menunjukkan kasih karunia-Nya kepada Daud dan juga Daud menunjukkan penyesalan yang sungguh-sungguh ketika Daud ditegur dosanya.

\section{Peristiwa Amnon Memperkosa Tamar (2Sam. 13:1-14)}

Amnon masih memiliki hubungan saudara dengan Tamar, namun Amnon terpesona kepada Tamar adik Absalom. Lalu ia membuat rancangan untuk dapat tidur dengan Tamar dengan cara berpura-pura sakit. Lalu meminta Tamar menyediakan kue baginya pada moment itulah ia melakukan tindakan immorality. Peristiwa itu menunjukkan sebuah perbuatan immorality yaitu perzinahan sesama saudara atau yang dikenal dengan insects. Karena nafsunya Amnon bisa merancangkan hal jahat untuk mencapai keinginannya. Hal itu menunjukkan manusia yang telah terjerat nafsu maka dia akan merancangkan cara untuk memuasakan nafsunya.

Bagaimana tindakan Allah terhadap kasus Amnon terhadap Tamar?. Jika kita melihat Alkitab Absalom marah dan akhirnya menyuruh orang untuk membunuh Amnon ketika ada pesta anak-anak raja Daud (lih. 2Sam. 13:28). Dalam peristiwa ini menunjukkan bahwa hukuman terhadap dosa immorality sangat tegas, dalam konteks ini juga sepuluh

${ }^{32}$ G. Sudarmanto, Pelayan Kristus...., 33

33 Ed. Charles F. Pfeiffer dan Everett F. Harrison, The Wycliffe, ...., 802 
hukum sudah ada dan salah-satu perintahnya menuliskan jangan berzinah (Kel. 20:14) dan

Dalam Imamat 18:9 menyatakan bahwa pernikahan dengan saudara tiri dilarang. ${ }^{34}$ Apabila kita melihat konteks dimana Amnon tidak menunjukkan penyesalan tetapi menjadi benci kepada Tamar dan merasa hal tersebut tidak perlu dipertanggungjawabkan maka Amnon juga mendapat konsekwensi yang tegas dari orang suruhan Absalom.

\section{Perempuan Berzinah Yang Diperhadapkan Kepada Yesus (Yoh. 8:1-11)}

Dalam Perjanjian Baru (PB) Yesus juga berhadapan dengan kasus tentang perzinahan. Kelompok orang Farisi dan ahli Taurat mencobai Yesus dengan kasus perzinahan. Waycliffe menuliskan motif orang-orang Farisi dan ahli-ahli Taurat ialah mencobai Yesus, mereka juga menunjukkan hukum mengenai perzinahan dalam Ulangan 22:23-24 yang hukumannya ialah dirajam batu. ${ }^{35}$ Bagaimana Yesus menyelesaikan kasus ini? Tuhan Yesus mengatakan siapa yang tidak berdosa dialah yang boleh melempar lebih dahulu wanita itu dengan batu. Mengenai hal tersebut Wycliffe menuliskan:

"kata-kata Yesus menyebabkan berpidahnya perhatian dari Yesus dan perempuan itu kepada para penuduh. Hati nurani mereka mulai bekerja. Mulai dari yang tertua. Usia menjadikan mereka pemimpin, dan pengalaman yang lebih lama dengan dosa membuat mereka lebih mudah tertuduh hati nuraninya."36

Yesus dapat saja melemparkan batu kepada perempuan itu, sebab Dia tanpa dosa; tetapi Dia lebih memperhatikan pemulihan orang berdosa. Wycliffe menuliskan iatilah "Aku pun tidak menghukum engkau" kalimat ini kedengaran terlalu lunak terhadap dosa, maka hal tersebut diimbangi oleh kelanjutannya "pergilah dan jangan berbuat dosa lagi". ${ }^{37}$ Maka tanggungjawab wanita tersebut lebih berat, karena harus menjaga hidupnya agar tidak jatuh ke dalam dosa.

\section{KONSEP IMMORALITY}

Konsep immorality yang dimaksud ialah rumusan ajaran secara sistematis mengenai immorality yang didasarkan pada fakta-fakta Alkitab.

\section{Bentuk-bentuk immorality dan Evaluasi Theologis}

Dari beberapa peristiwa Alkitab maka dapat disimpulkan bentukbentuk tindakan yang masuk dalam kategori immorality yaitu:

\section{Poligami}

\footnotetext{
${ }^{34}$ Ed. Charles F. Pfeiffer dan Everett F. Harrison, The Wycliffe, ...., 804

35 Ed. Charles F. Pfeiffer dan Everett F. Harrison, The Wycliffe, ...., 335

36 Ibid,..., 335

37 Ibid,..., 335
} 
Poligami ialah sistem perkawinan yang salah satu pihak mengawini dua orang lebih dalam satu kurun waktu; bermadu. ${ }^{38}$ Prinsip ini telah kita lihat dalam kehidupan awal manusia pada keluarga Lamekh. Perkembangan sistem poligami ini juga dianut oleh kelompok agama Islam yang menyetujui adanya poligami dengan dasar keadilan. Namun apakah benar demikian menurut Alkitab?. Dari permulaan Allah telah menetapkan lakilaki dan perempuan bersatu dan akan meninggalkan orang tua mereka dan menjadi satu daging. Jadi Allah menghendaki keluarga dibagun oleh sepasang manusia dalaam pernikahan yang monogami. Tuhan Yesus juga tidak menghendaki terjadinya perceraian, perceraian terjadi hanya karena kekerasan hati manusia. Oleh karena itu pernikahan dibangun untuk memuliakan Allah dalam kesatuan kasih pasangan suami istri untuk mengasihi Allah.

\section{Homoseksual}

Homoseksual merupakan gabungan dari kata homo (satu) dan seks, yang diartikan secara leterlak yaitu hubungan seks sesama jenis. ${ }^{39}$ Homoseksualitas menunjukkan ketertarikan hubungan dengan sesama jenis. Di dalam Alkitab fakta demikian terlihat dalam kasus Sodom dan Gomora yang ingin melakukan aksi sodomi kepada dua tamu Lot. Semangat homoseksualitas tersebut tidak padam namun terus berkembang dalam kemasan baru pada masa kini. Saat ini ialah munculnya komunitas LGBT (Lesbian, Gay, Biseksual dan Transeksual) beberapa negara mulai melegalisasi pernikahan sejenis dan menetapkan Gereja sebagai sarana pemberkatan pernikahan sejenis tersebut. Apakah ini Alkitabiah?. Dalam Roma 1:26-28 menyatakan bahwa orang-orang yang terlibat dalam penyimpangan seks bisa saja karena Allah telah menghukum mereka dengan menyerahkan mereka kepada pikiran-pikiran mereka yang terkutuk. Jika kita meninjau pada masa penciptaan manusia Allah mempertemukan Adam dengan Hawa yaitu laki-laki dan perempuan dipersatukan menjadi satu daging (Kej. 2:21-25).

Jadi tidak benarkan adanya homoseks dan pemberkatan nikah kepada pasangan LGBT. Lalu Allah juga telah menetapkan bahwa orang-orang yang melakukan seks menyimpang tidak mendapat bagian dalam kerajaan Allah (lih. 1Kor. 6:9-10), oleh karena itu penyimpangan seks dalam konteks homoseksualitas harus dihentikan karena itu dosa (lih. Im.20:13). ${ }^{40}$ Roma 6:23 menyatakan bahwa upah dosa adalah maut, tetapi kasih

38 Tim Prima Pena, Kamus Besar Bahasa Indonesia (Gitamedia Press), 620

39 Tim Prima Pena, Kamus...., 329

40 Imamat 20: 13 "Bila seorang laki-laki tidur dengan laki-laki secara orang bersetubuh dengan perempuan, jadi keduanya melakukan suatu kekejian, jadi keduanya melakukan suatu kekejian, pastilah mereka dihukum mati." (TB) 
karunia Allah ialah hidup kekal. Oleh karena seks dihadirkan Allah untuk memuliakan Allah bukan untuk memuaskan nafsu manusia.

\section{Incest}

Incest ialah sebuah istilah yang digunakan untuk menunjukkan tindakan seksualitas terhadap sesama anggota keluarga/saudara kandung. Jarot Wijanarko menuliskan penyimpangan seks membuat orang melakukan seks yang menyimpang (kebejatan seksual) seperti incest (seks dengan anak atau orang tua). ${ }^{41}$ Kasus ini terjadi dalam keluarga Lot dan kedua putrinya serta keluarga Daud antara Amnon dan Tamar memang mereka satu bapak beda ibu namun mereka tetap saudara karena satu ayah. Incest adalah perbuatan yang tidak memuliakan Allah. Lalu muncul pertanyaan, bagaimana dengan manusia mula-mula, menikah dengan siapakah mereka? Pada permulaan manusia mau tidak mau manusia menikah dengan saudaranya. Namun motivasi pada waktu menikah tersebut bukan untuk memuaskan nafsu namun untuk memenuhi muka bumi (lih. Kej. 1:28).

Dosa yang mempengaruhi kehidupan manusia telah menghancurkan motivasi utama pernikahan manusia. Namun setelah manusia semakin banyak maka hukum pernikahan dibentuk agar manusia memiliki etika yang benar dalam pernikahan. Maka ini juga menunjukkan bahwa anak-anak Lot juga memiliki motivasi yang salah dalam meneruskan keturunan bagi ayahnya, kedua anak Lot dan Lot sendiri tentulah telah dipengaruhi oleh budaya dari kerusakan moral penduduk Sodom (bdg. Kej. 13:13, 19:8), sehingga mereka melakukan hubungan seks diluar pernikahan, kepada orang tua sendiri dan pastilah untuk memenuhi hasrat seksualitas mereka. Dimana pernikahan untuk memuliakan Allah menjadi pernikahan untuk kepuasan seksualitas semata, jika incest dilegalkan maka di dalam kehidupan keluarga akan terjadi kekacuan karena manusia dapat dengan mudahnya memuaskan nafsu kepada saudaranya. Dalam PL incest sudah mulai dilarang, dalam Imamat 20:17 menegaskan bahwa incest akan mendapatkan hukuman. ${ }^{42}$ Oleh karena itu incest sebagai salah satu bentuk immorality yang dapat merusak keharmonisan kehidupan rumah tangga (lih. Im. 18:6).

41 Jarot Wijanarko, Selingkuh dan Sex, (Jakarta: Suara Pemulihan, 2007), 43

42 Imamat 20:17 "Bila seorang laki-laki mengambil saudaranya perempuan, anak ayahnya atau anak ibunya, dan mereka bersetubuh, maka itu suatu perbuatan sumbang, dan mereka harus dilenyapkan di depan orang-orang sebangsanya; orang itu telah menyingkapkan auarat saudaranya perempuan, maka ia harus menanggung kesalahannya sendiri." (TB) 


\section{Pemerkosaan}

Pemerkosaan memiliki arti pemaksaan. ${ }^{43}$ Bentuk immorality berikut dapat kita temukan dalam fakta Alkitab dalam kasus Dina dan Sikhem, Amnon dan Tamar. Mereka memaksa melakukan hubungan seks kepada lawan jenis. Bahkan jika dilihat ada keterkaitan antara incest dan pemerkosaan. Terkadang incest terjadi bisa saja dengan pemerkosaan. Sangat jelas bahwa hubungan seks di luar pernikahan sama saja dengan melakukan perzinahan. Hubungan seks di dalam pernikahan juga harus didasaarkan pada cinta kasih bukan nafsu. Pemerkosaan menunjukkan hawa nafsu sebagai dasar hubungan seks, akibatnya pemerkosaan bisa terjadi kepada saudara kandung, atau pun orang lain, dan bisa melanggar dari aturan dalam hal pernikahan. Beberapa kasus dalam Alkitab mencatat bahwa orang-orang yang melakukan pemerkosaan menghadapi konsekuensi moral-sosial, contohnya Sikhem dibunuh oleh Simeon dan Lewi, Lalu Amnon yang menodai Tamar dibunuh oleh orang suruhan Absalom. Namun dalam Ulangan 22:28-29 menyatakan bahwa laki-laki yang berzinah dengan seorang perawan masih diberi kesempatan untuk menebus kesalahannya. ${ }^{44}$ Secara sosial pemerkosaan tidak diterima dalam kehidupan masyarakat. Allah ada pribadi yang kudus, sehingga umatnya juga harus menjaga kekudusan. Oleh karena itu tindakan pemerkosaan masuk dalam kategori ketidakkudusan hidup, sehingga pemerkosaan adalah dosa. Namun dasar pertama yang harus dilakukan dalam penyelesaian masalah tersebut ialah kasih, sehingga manusia tetap memberi kesempatan kepada pelaku untuk bertobat atau menebus kesalahannya.

\section{Perselingkuhan}

Perselingkuhan digambarkan dalam bentuk mendua hati, dimana seorang yang telah menikah namun mejalin hubungan lain. Kasus perselingkuhan ini diperlihatkaan dalam kehidupan Daud dan Betsyeba. Dalam Imamat 18:20 menuliskan bahwa jangan menghampiri istri sesama. ${ }^{45}$ Hal tersebut menunjukkan perselingkuhan juga melanggar kekudusan hidup. Oleh karena itu manusia harus tetap menjaga kesetiaan pernikahan dengan pasangannya. Mengenai hal perkawinan Rasul Paulus menekankan dalam 1Korintus 7:3-4 yang menyatakan bahwa suami-istri harus saling memenuhi

43 Tim Prima Pena, KBBI, ..,604

44 Ulangan 22:28-29 "Apabila seorang bertemu dengan seorang gadis, yang masih perawan dan belum bertunangan, memaksa gadis itu tidur dengan dia, dan keduanya kedapatan - maka haruslah laki-laki yang sudah tidur dengan gadis itu memberikan lima puluh syikal perak kepada ayahnya, sebab laki-laki itu telah memperkosa dia; selama hidupnya tidak boleh laki-laki itu menyuruh dia pergi”

${ }^{45}$ Imamat 18:20 "Dan janganlah engkau bersetubuh dengan istri sesamamu, sehinggaa engkau menjadi najis dengang dia.” (TB) 
kewajibannya. ${ }^{46}$ Kewajiban tersebut secara prinsipil yaitu istri tunduk kepada suami dan suami mengasihi istri (Lih. Ef. 5:22-25; Kol.3:18-19). Jika kedua prinsip tersebut hadir dalam pernikahan suami istri maka akan meredam terjadinya perselingkuhan, secara prinsip orang yang mendua hati tidak akan tenang hidupnya (bdg.Yak. 1:8 Prinsip Yakobus terhadap mendua hati dalam konteks beriman). ${ }^{47}$

\section{Tunasusila}

Tunasusila artinya tidak punya susila, pelacur. ${ }^{48}$ Dalam fakta Alkitab perbuatan seperti ini dilakukan oleh Tamar menantu Yehuda yang menyamar sebagai wanita tunasusila dalam konteks tersebut Yehuda benar-benar tidak tahu bahwa itu menantunya, tindakan Yehuda membayar wanita tersebut menunjukkan Yehuda berpikir wanita itu membutuhkan harta. Tunasusila atau pelacur jika dihubungkan dalam konteks masa kini lebih cenderung kepada wanita yang lebih berfokus dalam hal memenuhi kebutuhan ekonomi dengan cara menjual jasa seks. Dalam konteks PL istilah tunasusila disebut dengan pelacur. Dalam PL ada istilah pelacur bakti, yaitu orang-orang yang melakukan pelacuran sebagai ritual penyembahan kepada berhala (bdg. Ul. 23:17). Dalam Amsal 29:3 menyatakan bahwa orang yang bergaul dengan pelacur memboroskan harta. Pelacuran dinilai sebagai lambang ketidaksetiaan (bdg. Hos. 3:1). Dalam Perjanjian Baru Tuhan Yesus juga menghadapi kasus demikian, ketika wanita yang dicap pelacur diperhadapkan padanya. Dalam Taurat hukuman bagi pelacur tersebut ialah dirajam dengan batu (Ul. 22:22-23), namun Tuhan Yesus memberikan pengampunan kepada perempuan itu, bukan karena mengabaikan Hukum Taurat tetapi Tuhan Yesus tahu hukum apa yang dahulu diterapkan kepada pelacur tersebut dan hukum yang pertama yang diberikan Tuhan Yesus ialah hukum kasih, yaitu pengampunan dan penekanan untuk tidak melakukan lagi perbuatan dosa yang sama. Pelacuran melanggar kekudusan dan kesetiaan oleh karena itu pelacuran itu dosa.

\section{Perzinahan}

Perzinahan di dalam Alkitab dapat dilihat dari sisi rohani dan fisik. Secara rohani perzinahan sama dengan menduakan Tuhan Allah atau melakukan penyembahan kepada berhala. Namun secara fisik perzinahan diperlihatakan dengan hubungan seks yang dilakukan oleh pasangan yang belum diberkati dalam pernikahan. Perzinahan dalam fakta Alkitab terdapat dalam kasus Yehuda dan Tamar hal tersebut ditentang dalam Imamat

\footnotetext{
${ }^{46}$ 1Korintus 7:3-4 "Hendaklah suami memenuhi kewajibannya terhadap istrinya, demikian pula istri kepada suaminya. Istri tidak berkuasa atas tubuhnya sendiri, tetapi suaminya, demikian pula suami tidak berkuasa atas tubuhnya sendiri, tetapi istrinya."

47 Yakobus 1:8 "sebab orang yang mendua hati tidak akan tenang dalam hidupnya."

48 Tim Prima Pena, KBBI,..., 777
} 
20:12 dan hukumannya ialah hukuman mati. ${ }^{49}$ Dalam Amsal 5:20 larangan untuk bergaul dengan perempuan jalang ditekankan. ${ }^{50}$ Perzinahan antara manusia dengan binatang atau yang dikenal istilah animal sex juga dilarang (lih. Im. 20:15-16). Pada masa kini perzinahan telah berpadu dengan teknologi. Penyimpangan seks dengan memakai teknologi pada masa kini disebut cybersex. ${ }^{51}$ Perzinahan melanggar kekudusan Allah sehingga perzinahan adalah dosa.

\section{IMPLIKASI IMMORALITY}

Immorality telah mempengaruhi dalam banyak bidang kehidupan manusia, baik itu politik, ekonomi, pendidikan, seni, filosofi dan gereja, pengaruh tersebut dapat terlihat dalam aspek spiritualitas, etika dan sosial. Pertama, dalam aspek spiritualitas immorality membentuk sebuah kemunduran rohani dalam membangun tubuh Kristus, immorality melahirkan ketidakkudusan dalam kehidupan manusia, kondisi tersebut membuat manusia mengalami kerentanan terhadap berbagai macam dosa. Immorality bisa membuat sensitifitas rohani menjadi tumpul, sehingga mempengaruhi pola pikir dan emosional manusia. Oleh karena itu setiap manusia yang terikat dalam dosa immorality tidak bisa memikirkan berbagai aspek kehidupan manusia secara rohani.

Kedua, dalam aspek etika immorality membentuk manusia yang hidup dalam etika yang tidak sesuai dengan Alkitab. Immorality memberikan perubahan hidup dan nilai dalam sikap manusia terhadap kebebasan. Immorality mempersempit pemahaman manusia akan kebebasan, sehingga manusia yang hidup dalam ikatan immorality melakukan prinsip etika yang terikat oleh dosa. Immorality membebaskan tindakan dosa untuk dilakukan sehingga kehidupan akan menjadi hidup tanpa etika. Etika yang tidak bermoral itulah yang menjadi etika manusia yang terikat dalam immorality.

Ketiga, dalam aspek sosial immorality membentuk komunitas yang tidak bermoral, sebagai contoh munculnya komunitas LGBT. Immorality mempengaruhi kebersamaan manusia sehingga terbentuklah kotak-kotak kehidupan. Karena komunitas yang tak bermoral tidak bisa bergabung dengan komunitas bermoral. Jika terjadi

49 Imamat 20:12 "Bila seorang laki-laki tidur dengan menantu perempuan, pastilah keduanya dihukum mati; mereka telah melakukan suatu perbuatan keji, maka darah mereka tertimpa kepada mereka sendiri." (TB)

50 Amsal 5:20 "Hai anakku, mengapa engkau berahi kepada perempuan jalan, dan mendekap dada perempuan asing" (TB)

51 Cybersex adalah segala bentuk aktifitas sexual (dalam alam maya) yang menguasai / mengontrol pikiran manusia dengan menggunakan teknologi komputerisasi (internet). Gunaryo Sudarmanto, Menjadi Pelayan...., 30 
kebersamaan maka akan terjadi penghakiman dari salah satu pihak. Pihak yang tidak bermoral akan membela diri atas nama HAM, lalu pihak yang bermoral akan membela diri dengan dasar agama.

Siapa pun yang terikat dalam dosa immorality apa pun bidang kehidupan yang dijalani baik dalam duania politik, ekonomi, pendidikan, seni, filsafat dan gereja baik secara spiritual, etika dan sosial akan menghasilkan perbuatan dan tindakan yang immorality seperti yang telah dipaparkan dalam latar belakang. Dari ketiga aspek yang mendapat dampak dalam immorality hal yang perlu dilakukan secara pastoral ialah seperti Tuhan Yesus lakukan terhadap wanita yang dibilang berzinah, Yesus tidak meringankan hukuman terhadap perzinahan tetapi Yesus lebih tahu hukum apa yang harus diterapkan lebih dahulu kepada orang yang berzinah itu, Yesus menerapkan hukum kasih terlebih dahulu daripada memakai otoritas untuk menghakimi. Jadi terapkanlah hukum yang utama yaitu kasih bagi orang-orang yang terjebak dalam immorality. Implikasi dari immorality yang paling bahaya ialah dalam ranah eskatologis yaitu ketidakselamatan manusia atau tidak mendapat bagian dalam kerajaan Allah. Oleh karena itu implikasi ini hanya dapat diselesaikan oleh kasih karunia Allah bagi manusia.

\section{PENUTUP}

Immorality merupakan perbuatan yang tidak bermoral yang berorientasi pada seksualitas. Immorality bertentangan dengan kekudusan Allah, sehingga immorality adalah dosa. Allah memiliki banyak cara untuk menangani kasus immorality, namun yang paling penting ialah menerapkan hukum kasih lebih utama dalam penanganan terhadap immorality. Immorality dapat dilakukan dalam berbagai bentuk penyimpangan, seperti poligami, homoseks, perselingkuhan, pemerkosaan, tunasusila dan perzinahan. Immorality adalah dosa serius di hadapan Tuhan, oleh karena itu setiap manusia yang terjebak dalam kehidupan yang immorality tiada jalan lain selain anugerah pembaharuan hidup oleh Allah. 


\section{DAFTAR PUSTAKA}

A. Tucker, Ruth, 2007 Another Gospel, Malang: Gandum Mas

B. Lumintang, Ramly,

2010 Bahaya Postmodernisme \&amp; Peranan Kredo Reformed, Batu: Departemen Literatur PPII

F. Pfeiffer, Charles dan Everett F. Harrison (Ed),

2011 The Wycliffe Bible Commentary, Malang: Gandum Mas

F. Walker, D,

2009 Konkordansi Alkitab, Jakarta: PT. BPK. Gunung Mulia

F. Wilbur Gingrich dan Frederick W. Danker (Ed.),

1987 A Greek-English Lexicon of The New Testament and other

Early Christian Literature, Chicago: The University of Chicago Press

Handol, John,

2002 Nyayian Lucifer, Yogyakarta: ANDI

Henry, Matthew,

2014 Kitab Kejadian, Surabaya: Momentum

J. Grenz,Stanley,

2009

A Primer On Postmodernism,

K. Kuiper, B, Yogyakarta: ANDI Offset

$2010 \quad$ The Church in History, Malang:

Gandum Mas

Kuhl, Dietrich,

1997 Sejarah Gereja: Gereja Katalik Roma Jilid 2,

Batu: Departemen Literatur YPPII

M. Echols, John \& Hassan Shadily

$2010 \quad$ Kamus Inggris Indonesia, Jakarta: PT. Gramedia

Park, Abraham,

2013 Sejarah Penebusan: Silsilah Di Kitab Kejadian Vol. 1

Jakarta: PT. GRASINDO

2012 Sejarah Penebusan: Pertemuan Yang Tak Terlupakan, Jakarta: PT. GRASINDO

Prima Pena, Tim,

---- $\quad$ Kamus Besar Bahasa Indonesia, Gitamedia Press

Peter Lange, Johann

1893 Commentary on Holy Scripture: Critical, Doctrinal and HomileticalGenesis, Trans. And ed. Philif Schaff, Grand Rapids: Zondervan

S. Borong, Robert,

2006 Etika Seksual Kontemporer

Sudarmanto, Gunaryo,

2009 Be A Good Minister of Christ, Batu: Departemen Literatur YPPII

Sutanto, Hasan,

$2010 \quad$ Perjanjian Baru Interlinear Yunani-Indonesia dan Konkordansi Perjanjian Baru (PBIK) Jilid I, Jakarta: Lembaga Alkitab Indonesia 
$2010 \quad$ Perjanjian Baru Interlinear Yunani-Indonesia dan Konkordansi Perjanjian Baru (PBIK) Jilid II, Jakarta: Lembaga Alkitab Indonesia

Ten Napel, Henk

2010

Kamus Teologi, Jakarta: BPK. Gunung Mulia

Wijanarko, Jarot,

2007 Selingkuh dan Sex, Jakarta: Suara Pemulihan 